\title{
O PRINCÍPIO CONSTITUCIONAL DA SOLIDARIEDADE COMO FUNDAMENTO DO DIREITO SOCIAL À ASSISTÊNCIA SOCIAL, DA DOUTRINA DA DASEINSVORSORGE E DO MÍNIMO EXISTENCIAL. POSSIBILIDADES E LIMITES EM ÉPOCA DE PANDEMIA SANITÁRIA.
}

\author{
Álvaro Russomano Goñi ${ }^{1}$
}

\begin{abstract}
Resumo
O estudo analisa o princípio da solidariedade como fundamento dos institutos da daseinsvorsorge, e assim se relacionam às políticas públicas adotadas para garantir a efetividade do direito à assistência social em tempos de COVID-19 no Brasil. Desenvolve-se através do método hipotético dedutivo e considera que as políticas públicas assistenciais estão baseadas no princípio da solidariedade e asseguram o mínimo existencial. A pesquisa é documental e bibliográfica. Estuda as possíveis semelhanças e diferenças entre a daseinsvorsorge e o mínimo existencial e, após, o princípio da solidariedade e o direito à Assistência social no âmbito da Constituição Federal.
\end{abstract}

Palavras-chave: daseinsvorsorge; mínimo existencial; princípio da solidariedade; direito social à assistência social; pandemia;

\section{THE CONSTITUTIONAL PRINCIPLE OF SOLIDARITY AS THE FOUNDATION OF THE SOCIAL RIGHT TO SOCIAL ASSISTANCE, THE DOCTRINE OF DASEINSVORSORGE AND THE EXISTENTIAL MINIMUM.}

\begin{abstract}
The study analyzes how the daseinsvorsorge institutes, existential minimum and solidarity principle are related to the public policies adopted to guarantee the effectiveness of the right to social assistance in COVID-19 times in Brazil. It is developed through the hypothetical deductive method and considers that public assistance policies are based on the principle of solidarity and ensure the minimum existential. The research is documentary and bibliographic. In the first chapter it studies the possible similarities and differences between daseinsvorsorge and existential minimum and in the second the principle of solidarity and the right to social assistance under the Federal Constitution.
\end{abstract}

Key words: daseinsvorsorge; existential minimum; principle of solidarity; social right to social assistance; pandemic;

\section{INTRODUÇÃO}

\footnotetext{
*Mestrando em Direito pelo Programa de Pós-Graduação em Direito da Universidade Federal de Pelotas (UFPEL), especialista em Direito Constitucional Aplicado, Pós-Graduando em Direito Previdenciário. Advogado.
} 
No contexto de pandemia mundial de Coronavírus SARS-COV2, a Organização Mundial da Saúde (OMS) recomendou que os Estados adotassem medidas de isolamento social. No Brasil tal orientação se materializou na Recomendação ${ }^{\circ} 27$ do Conselho Nacional de Saúde (BRASIL, 2020) para estimular a busca pelo achatamento da curva de propagação do vírus.

As medidas adotadas pelos entes governamentais trouxeram diversas consequências no cotidiano dos cidadãos, dentre as quais salienta-se o afastamento dos indivíduos de suas atividades econômicas. Em razão disso, mostra-se relevante a adoção e o estudo de políticas públicas que visem a garantir o sustento dos cidadãos durante o período de pandemia. No Brasil foram seguidas medidas de isolamento social e o Estado brasileiro pôs em prática políticas as quais visaram garantir recursos financeiros destinados à manutenção dos cidadãos.

A mencionada atuação estatal se desenvolve por meio de medidas assistenciais e está baseada no princípio da solidariedade, o qual possui matriz constitucional, no artigo $3^{\circ}$, inciso I, da Constituição Federal de 1988 (CRFB). Construir uma sociedade solidária constitui objetivo fundamental da República Federativa do Brasil. Ao lado disso, a CRFB estabelece no artigo $6^{\circ}$, caput, que a assistência social constitui um direito social.

Através dos serviços públicos essenciais o Estado age para suprir as necessidades ligadas à existência dos indivíduos consagradas no artigo $6^{\circ}$, caput, da CRFB. Essa tutela das necessidades se dá por meio das políticas públicas desenvolvidas e aplicadas pelos Poderes Executivo e Legislativo. As políticas públicas se traduzem, também, em serviços de interesse público, como o daseinsvorsorge oriundo do Direito Alemão, que consiste nos serviços de interesse público que devem ser prestados, pelo Estado aos cidadãos desvalidos - e.g programas de transferência permanente ou temporária de renda) e fundamentados no princípio da solidariedade social têm por finalidade assegurar aos cidadãos o mínimo existencial. Mínimo existencial este que possui origem no direito alemão e em apertada síntese consiste em condições materiais básicas para o exercício das liberdades básicas dos indivíduos.

Por esses motivos o presente artigo se propõe a estudar de que forma os institutos do daseinsvorsorge, do mínimo existencial e do princípio da solidariedade se relacionam com a concretização direito social à assistência social? Para tanto, em um primeiro momento serão estudados os institutos da daseinsvorsorge e do mínimo existencial, com a abordagem de seus 
conceitos, similaridades e diferenciações e implicações, bem como seus reflexos na compreensão do direito social à assistência social. A base teórica do instituto do daseinsvorsorge utilizada é a obra de Ricardo Lobo Torres, considerado o precursor do tema no direito pátrio. Com relação ao mínimo existencial serão analisados conceitos doutrinários, bem como possíveis dimensões do instituto e formas de sua concretização. Será estudado o princípio constitucional da solidariedade interligado aos já citados institutos com vistas nas ações do Governo Federal adotadas prévia e concomitante à pandemia de COVID-19 e será analisado a partir do texto constitucional brasileiro, com a abordagem de doutrinas e artigos científicos sobre o tema.

Será estudado, ainda, o direito social à assistência social, elencado no rol de direitos sociais do artigo $6^{\circ}$ da $\mathrm{CRFB}$, bem como as legislações nacionais e internacionais que possam servir como fundamento de todos os institutos descritos, com ênfase naquelas espécies normativas que tratem especialmente da Assistência Social no Brasil pós Constituição de 1988 e também nas proposições legislativas editadas durante a pandemia de COVID-19 no Brasil, bem como decisões judiciais que sejam condizentes com a discussão. A relevância e pertinência do presente estudo baseia-se na ausência de trabalhos que analisem o tema sob a perspectiva ora proposta e na íntima relação entre as políticas públicas de assistência social e a garantia de condições mínimas de sobrevivência aos cidadãos. Logo, o presente trabalho tem por objetivo analisar como o princípio da solidariedade, o daseinsvorsorge e o mínimo existencial atuam na concretização do direito social à assistência social no Brasil durante a pandemia de COVID-19.

\section{DASEINSVORSORGE E O MÍNIMO EXISTENCIAL.}

Daseinsvorsorge é expressão originária da Alemanha, cujo significado literalmente é "interesse geral". O termo foi cunhado por Ernst Forsthoff, advogado constitucionalista alemão, falecido na década de 1970. Segundo J.J. Gomes Canotilho interesse geral, service publique, são serviços garantidores de cidadania social e econômica quanto aos bens públicos essenciais, que seriam bens sociais os quais na função de Estado Social seriam considerados 
bens públicos e que deveriam ser prestados pelo Estado (CANOTILHO, 2008). Em um estudo pioneiro sobre o tema no Brasil, Ricardo Lobo Torres afirma que Daseinsvorsorge são serviços públicos que o Estado, através de subvenções sociais, deve fornecer aos desvalidos e desamparados, que por si só não conseguem prover a sua existência (TORRES, 1989).

Em suma, daseinsvorsorge caracteriza pelos serviços de interesse público que o Estado deve fornecer aos indivíduos os bens e serviços, os chamados suprimentos básicos considerados necessários à existência.

Igualmente originário do direito alemão, o instituto do mínimo existencial muito se aproxima da face material do daseinvorsorge. Explica-se: o mínimo existencial assume no presente artigo o caráter de princípio protetivo do indivíduo contra investidas estatais no escopo de retirar direitos e também como mecanismo assegurador de um certo quantum de prestações positivas que visem assegurar além de uma mera existência aos indivíduos, uma existência digna, como ensinam Torres (1989) e Sarlet (2019).

Ricardo Lobo Torres ao abordar o tema leciona que o mínimo existencial é caracterizado com um direito às condições de existência humana digna e que não podem ser afetados pelo Estado e que ainda exige prestações estatais positivas (TORRES, 1989).

Conceituado de maneira simplista, o mínimo existencial consiste em um conjunto de condições necessárias para que seja assegurada a dignidade, em observância deste mínimo como um limite pessoal de subsistência que não poderá ser desrespeitado (LAZARI, 2016). É uma linha de proteção mínima a favor dos indivíduos, que impõem ações materiais de todas as esferas de governo destinadas a proporcionar condições mínimas de existência e não só existência, mas digna

Aqueles que não possuem condições de autossustento, que necessitam de prestações estatais para que tenham assegurado o sustento, a sobrevivência, têm direito a um auxílio do Estado (SARLET, 2016).

A atuação estatal na garantia do mínimo existencial não é uma conduta de bondade, discricionária, ao alvitre do administrador público, mas sim decorrente imediata do comando constitucional, que por si, dá coercibilidade às regras definidoras de direitos e instituidora de garantias fundamentais. Há parcela da doutrina que milite a favor da intangibilidade do 
mínimo existencial, inclusive afastando-a da ponderação com o princípio da reserva do possível (TORRES, 1989).

A concretização das prestações positivas, exigíveis pelos indivíduos, deve ser pautada pela responsabilidade fiscal, no entanto, não devem prevalecer os pontos de vista econômicos sobre os fundamentos jurídicos, sob pena de precificação de direitos fundamentais. Não se pode descuidar, contudo, que a análise econômica do direito está em voga nos últimos tempos, face a proeminência do discurso neoliberal (ROSA, 2012), o que pode ter gerado uma deficiente proteção social, inclusive durante a pandemia COVID-19.

Os direitos sociais que impõem ao Estado uma prestação positiva em favor do indivíduo, pretendem ao fim e ao cabo, proteger as pessoas contra as suas necessidades materiais e servem como fundamento para justificar o direito fundamental ao mínimo existencial (SARLET, 2019). Segundo Ricardo Lobo Torres (1989), a doutrina suíça denomina o instituto como direitos sociais mínimos.

$\mathrm{Na}$ forma do que dispõe o Princípio 25 dos Princípios de Limburgo, os Estados possuem a obrigação de, independentemente do nível de desenvolvimento econômico, de garantir o respeito dos direitos de subsistência mínima de todas as pessoas.

Como exemplo de garantia de prestações mínimas, cita-se o disposto no artigo $4^{\circ}$ da Constituição do México, segundo o qual, às pessoas é assegurado o direito a uma alimentação suficiente e de qualidade, garantida pelo Estado (MÉXICO, 1917).

A Constituição da República Italiana, a qual em seu artigo 117, alínea “m” estabelece que cabe ao Estado legislar especificamente sobre a determinação dos níveis essenciais das prestações referentes aos direitos civis e sociais que devem ser garantidos em todo o território nacional (ITÁLIA, 1947).

É importante destacar que o mínimo existencial não é assegurado somente com o pagamento do benefício de prestação continuada tendo em vista que, embora este seja pago no montante equivalente a um salário mínimo nacional, ao idoso ou à pessoa com deficiência que não possa prover a sua subsistência ou de tê-la provida por sua família, a quantia não supre as necessidades básicas do indivíduo, como pretende o artigo $7^{\circ}$, inciso IV, da Constituição Federal de 1988 (BRASIL, 1988). Inclusive, conforme estudo do Departamento Intersindical 
de Estatística e Estudos Econômicos (DIEESE, 2020), o salário mínimo nominal em 2020 é de $\mathrm{R} \$ 1.045,00$ quando o salário mínimo necessário seria de $\mathrm{R} \$ 4.420,11$ no mês de julho de 2020.

Conforme Rafael de Lazari (2016) o mínimo existencial é considerado um princípio. Lazari (2016), segundo o qual tal natureza jurídica permite que seja ponderado com outros princípios igualmente relevantes como a reserva do possível, que atua como limitador material à concretização dos mandamentos constitucionais vinculados aos direitos sociais e, logicamente, à dignidade humana (LAZARI, 2016). O mínimo existencial deve funcionar como verdadeira barreira ao retrocesso (TORRES. 1989). São prestações sem as quais os indivíduos não podem sobreviver e, portanto, obrigações estatais que não podem ser condicionadas.

Como bem assevera Torres (1989), o fundamento para assegurar o mínimo existencial encontra-se justamente na criação de condições para que o indivíduo possa exercer as suas liberdades. Cidadão nenhum pode ser considerado livre, efetivamente, caso não seja provido dessas condições basilares de existência. Existir distingue-se da mera sobrevivência.

Em razão dessas considerações, inclusive, Rafael de Lazari em sua obra Reserva do Possível e Mínimo Existencial analisa detidamente o conteúdo do mínimo existencial em cada um dos direitos sociais estabelecidos no artigo $6^{\circ}$ da Constituição Federal de 1988 (LAZARI, 2016). O princípio da razoabilidade deve ser aplicado nesta seara, ao impedir que os indivíduos exijam do Estado prestações que não guardem uma relação de proporcionalidade e adequação com os fins a que se destinam e tampouco que as ações estatais estejam completamente condicionadas à discricionariedade dos poderes estatais, de forma que a razoabilidade funcione também como limite à inação estatal (BARROSO, 2013).

A concretização dos objetivos e a observância dos mandamentos constitucionais deve ocorrer por iniciativa dos Poderes Executivo e Legislativo, através da adoção de políticas públicas, as quais são conceituadas como a totalidade de ações, metas e planos que os governos traçam para alcançar o bem-estar da sociedade e o interesse público (CALDAS, 2008). Conforme Phillip Gil França (2013), políticas públicas consistem na organização de esforços do estado para alcançar objetivos previamente estabelecidos para realizar um interesse público constitucionalmente previsto. 
As subvenções sociais são expressão de uma política pública, na sua fase de implementação, e consiste na transferência de renda utilizada para assegurar condições de manutenção aos indivíduos que não tenham a possibilidade de fazer por si em razão de alguma condição pessoal, seja pela idade avançada, seja por apresentar alguma espécie de deficiência. De certa forma deve-se admitir que o mínimo existencial pode ser garantido através da prestação de serviços de interesse público, como políticas públicas de transferência de renda.

\section{A RELAÇÃO ENTRE O PRINCÍPIO DA SOLIDARIEDAdE E O DIREITO SOCIAL À ASSISTÊNCIA SOCIAL E OS INSTITUTOS DO DASEINSVORSORGE E DO MÍNIMO EXISTENCIAL NO BRASIL.}

No plano internacional, não há previsão expressa do princípio da solidariedade, embora seja extraído do preâmbulo da Declaração Universal dos Direitos Humanos (DUDH) em razão da expressão "membros de toda a família humana", conforme GODÓI (2005). Embora a compreensão de solidariedade seja expressão fundante de uma série de diretrizes de comportamento, como afirmam José Luis Bolzan de Morais e Guilherme Massaú, a solidariedade necessita de ligação a algum princípio porque de forma isolada não possui características jurídicas (MORAIS; MASSAÚ, 2011).

Já no âmbito interno, a solidariedade figura como objetivo fundamental da República Federativa do Brasil, como se retira do artigo $3^{\circ}$, inciso I, da CRFB. Este é o fundamento constitucional do princípio, o qual possui em outros dispositivos a forma exata de sua manifestação. Através dele o Estado figura como co-responsável pela existência digna dos indivíduos.

De acordo com Gilmar Ferreira Mendes e outros, o princípio da solidariedade fundamenta a Seguridade Social na vertente da Assistência Social, uma vez que abrange um conjunto de ações de iniciativa dos poderes públicos e da sociedade, com financiamento a cargo de toda a sociedade e acessíveis a quem dela necessitar independente de prévia contribuição (MENDES et al, 2008). 
Essa co-responsabilidade estatal pelo bem estar dos indivíduos decorre do fato de que após o advento da Lei de Bohn e o julgamento dos crimes de Nurenberg passa-se a reconhecer que o Estado existe em função da sociedade e não o oposto (REDONDO, 2019).

Adotamos aqui a acepção de solidariedade genérica (YAMASHITA, 2005), que é aquela espécie de solidariedade respeitante à toda sociedade e distingue-se da solidariedade de grupos sociais homogêneos ou a solidariedade orgânica proposta por Émile Durkheim (DUQUE, 2013). A solidariedade de grupos sociais consiste em interdependência baseada na diferenciação e que então as pessoas se inter-relacionam com base na cooperação (DUQUE, 2013). Não se considerará solidário aquele que age somente em busca de seus interesses, a solidariedade implica em renúncia a certas vantagens pessoais (ROSSO, 2007).

Mesmo assim, o princípio da solidariedade veio expressado como objetivo fundamental da República Federativa do Brasil no intuito de construir-se mais do que uma sociedade solidária. A solidariedade permeia e deve permear não só as relações interpessoais, como também as relações entre os entes públicos e os membros da sociedade. Por isso, fala-se na solidariedade do Estado para com os indivíduos.

A solidariedade deve ser normativa, não só baseada nas boas intenções ou nos pilares da Igreja, no sentido de se manifestar através de valores morais. A normatividade da solidariedade decorre essencial e primordialmente de sua previsão no texto constitucional.

Esta noção de solidariedade geral, que inclui a relação do Estado com os indivíduos deve ser trazida à tona no atual cenário brasileiro, visto que, como é de conhecimento público, no ano de 2020 o Brasil está sendo assolado pela pandemia de coronavírus, abreviadamente denominada de COVID-19. A enfermidade impôs uma série de restrições econômicas, de circulação e convívio social com o objetivo de atender às recomendações Organização Mundial da Saúde (OMS, 2020), com o objetivo de reduzir o contágio, permitir que os sistemas de saúde tenham capacidade de fornecer atendimentos aos pacientes necessitados e preservar vidas humanas.

Dentre os institutos que são a expressão do direito à assistência social elencamos o chamado Benefício de Prestação Continuada (BPC), previsto na Lei 8.742/1993, que é a regulamentação do mandamento inserido nos artigos $6^{\circ}$ da Constituição Federal de 1988, segundo o qual a assistência aos desamparados constitui um direito social. Já os direitos 
sociais de cunho prestacional (especialmente compreendidos como direitos a prestações fáticas) (...) objetivam, em última análise, a proteção da pessoa contra necessidades de ordem material, buscando assegurar uma existência digna (SARLET, 2019).

De acordo com Victor Abramovich e Christian Courtis (2011), os direitos sociais podem ser caracterizados como um complexo de obrigações positivas e negativas por parte do Estado, ainda que as obrigações positivas tenham uma importância simbólica maior.

Compete ao Estado a implementação de políticas públicas diversas objetivando determinados segmentos e suas legítimas expectativas (JUNIOR et al., 2018). À guisa de exemplo, conforme informação obtida do sítio do Instituto Nacional do Seguro Social (INSS), no Brasil são beneficiários do benefício de prestação continuada aproximadamente 4,6 milhões de pessoas entre idosos e pessoas com deficiência.

Sendo os direitos sociais a espécie dos direitos que asseguram a existência digna do indivíduo e, portanto, estão vinculados em certa medida ao mínimo existencial, e se os Estados signatários do Pacto Internacional de Direitos Econômicos, Sociais e Culturais PIDESC (como é o caso do Brasil e da Alemanha) estão vinculados igualmente os Princípios de Limburgo, os referidos Estados estão obrigados a assegurar ao menos níveis essenciais de cada um dos direitos (ABRAMOVICH et al, 2011). Ainda conforme os autores argentinos, o fundamento desta obrigação é extraído do artigo 20 do PIDESC, em interpretação realizada pelo Comitê.

A Carta dos Direitos Fundamentais da União Europeia, já em seu preâmbulo estabelece que a União Europeia baseia-se no valor indivisível e universal da solidariedade e prossegue, em seu artigo 34, item 3, garantindo um direito a uma assistência social condigna a todos que não possuam recursos suficientes para tanto. A citada Carta de Direitos Humanos vai além e assegura uma ajuda à habitação destinada à existência com dignidade dos indivíduos (CDFUE, 2009)

O direito à assistência social está previsto no artigo 22 da Declaração Universal dos Direitos do Homem de 1948 (DUDH), dispositivo este que assegura a todos os seres humanos o direito à segurança social, à realização, pelo esforço nacional, pela cooperação internacional 
e de acordo com a organização e recursos de cada Estado, dos direitos econômicos, sociais e culturais indispensáveis à sua dignidade e ao livre desenvolvimento da sua personalidade.

Deste citado artigo 22, podemos concluir que a assistência social tem por finalidade erradicar as desigualdades existentes entre os indivíduos, os quais devem ostentar condições de vida mínimas para o exercício da cidadania.

No Brasil, a assistência social é consagrada como um direito social, conforme disposto no artigo $6^{\circ}$ caput da CRFB 1988, assegurado através da Seguridade Social prevista a partir do artigo 194 da CRFB.

O artigo 203, da CRFB 1988, estabelece exatamente que a assistência social será prestada - é serviço público - a quem dela necessitar, independentemente de contribuição. Estabelece, ainda, os objetivos da Assistência Social.

Com o objetivo de regulamentar os dispositivos constitucionais, o legislador ordinário elaborou legislações como a Lei 8742/1993 (BRASIL, 1993) e Lei 12.435/2011, as quais criaram a Lei Orgânica da Assistência Social e a modificaram respectivamente.

Nesse contexto, os cidadãos brasileiros que exercem atividade econômica foram obrigados a abrir mão de sua autonomia individual e reduzir ou cessar o exercício profissional em prol da proteção individual e coletiva. É importante destacar que no cumprimento do denominado distanciamento social e em razão da crise econômica agravada pelo cenário de retração, no mês de abril de 2020, no Brasil, foram encerrados 860 mil postos de trabalho formais (BRASIL, 2020). Existe uma massa de pessoas desocupadas que atinge 13,3\% da população economicamente ativa (IBGE, 2020). No caso específico de desemprego involuntário há o socorro denominado Programa do Seguro Desemprego, inserido no início dos anos 1990 através da Lei 7.998/1990 (BRASIL, 1990), mas há aquelas pessoas que não conseguem prover por si o próprio sustento, muitas vezes sequer amparadas por benefícios de transferência de renda ou inacessíveis a benefícios inseridos na Lei Orgânica da Assistência Social porque não possuem idade avançada ou qualquer tipo de deficiência.

O contexto é similar ao vivenciado pela Europa já nos anos 1980, quando em razão da desaceleração da economia e da redução do Estado do Bem-Estar muitos indivíduos foram lançados para a margem da sociedade (BAHLE; HUBL, 2011). 
Com a finalidade de salvaguardar postos de trabalho e assegura uma quantia à população necessitada foi criado através da Medida Provisória (MP) $\mathrm{n}^{\circ} 936$ de $1^{\circ}$ de abril de 2020 o Programa Emergencial de Manutenção do Emprego e da Renda (PEMER), que consiste na transferência de recursos da União para aqueles indivíduos que preencham determinados requisitos, condizentes com a situação de maior vulnerabilidade social / desamparo. A referida MP foi convertida em lei pelo Congresso Nacional, a Lei 13.982/2020 (BRASIL, 2020), que inclusive promoveu alterações na Lei Orgânica da Assistência Social.

O PEMER implica na transferência de quantia mensal em um certo número de parcelas para aqueles que exerçam atividade informal ou não estejam amparados por nenhum outro benefício de transferência de renda do Governo Federal que seja mais vantajoso. Esse contexto é a nítida manifestação do dever estatal de responsabilidade pelos desamparados inserido no artigo $6^{\circ}$, caput, da Constituição Federal de 1988, que se fundamenta no princípio da solidariedade.

É certo, todavia, que o valor nominal transferido não é suficiente para suprir todas as necessidades, uma vez que para tanto deveria aproximar-se do salário mínimo nacional, garantido pelo artigo $7^{\circ}$, inciso IV, da CRFB de 1988. Conforme dados do Departamento Intersindical de Estatística e Estudos Socioeconômicos (DIEESE, 2020), o salário mínimo nominal no mês de abril de 2020 (mês da instituição do auxílio emergencial) foi de $\mathrm{R} \$ 1.045,00$ quando para suprir as necessidades básicas deveria ser de $\mathrm{R} \$ 4.673,06$, logo há uma visível disparidade entre o auxílio emergencial pago e as necessidades dos cidadãos, no entanto, essa foi a opção política realizada.

Destaque-se que a observância do ordenamento jurídico deve ocorrer por todos os indivíduos e principalmente pelo Estado, o qual tem as suas ações pautadas pela observância e concretização do princípio da dignidade humana, positivado através do artigo $1^{\circ}$, III, da Constituição Federal de 1988 (BRASIL, 1988).

Em julgado recentíssimo, datado de 5.11.2019, o Tribunal Regional Federal da $4^{\mathrm{a}}$ Região, asseverou justamente que, com base no princípio da solidariedade social não há, necessariamente, uma correlação entre a contribuição feita pelo contribuinte e a prestação estatal (BRASIL, 2019). Outro não poderia ser o entendimento, há a manifestação da 
solidariedade justamente para a contribuição com o bem comum, sem que o indivíduo obtenha qualquer ganho imediato e pessoal aferível.

A flexibilização do princípio da solidariedade no âmbito previdenciário impõe aos indivíduos que respondam por situações de vulnerabilidade para as quais não contribuíram necessariamente. Quer dizer, a vigorar o princípio da capitalização simples, em que cada indivíduo será responsável pela criação de um fundo que permita a aposentadoria ou o gozo de auxílios previdenciários, exonerando o Estado de servir justamente como a teia protetora dos desvalidos. Exemplificativamente, a solidariedade impõe a construção de um dique em uma área alagada, antes que ocorra uma inundação, no lugar de relegar às pessoas que individualmente busquem a sua própria segurança (WAAL, 2009).

A anteceder a abordagem relativa à associação entre daseinsvorsorge, mínimo existencial e princípio da solidariedade, é importante que se ratifique, como assevera Rafael de Lazari, que o conteúdo do princípio do mínimo existencial não é pacificamente definido pela doutrina brasileira (LAZARI, 2016).

Muito se ouve falar acerca da necessidade de concretização, por parte do Estado brasileiro, do mínimo existencial, no entanto, raramente vemo-nos voltados ao texto da Constituição Federal de 1988, o qual claramente disciplina de que forma isto deverá ocorrer. Excepcionalmente, como mencionado anteriormente, através do PEMER, o Governo Federal institui transferência provisória de renda que visa amenizar o total estado de pobreza e miserabilidade daqueles que foram mais atingidos pela recessão provocada pela COVID-19. Tal ação estatal vai ao encontro do que Márcio Augusto de Vasconcelos Diniz afirma, no sentido de que se destaca no Estado de Direito, Democrático e Social o dever do Estado de proteger os cidadãos quanto à supressão ou diminuição dos meios de subsistência (DINIZ, 2007).

A Europa possui instituto de relevo na seara da assistência social, denominado, conforme Thomas Bahle e Vanessa Hubl (2011), de minimum income protection (proteção de renda mínima), e no ano de 2007 na Irlanda e no Reino Unido 20\% das pessoas idosas dependiam dessa renda, enquanto no mesmo ano $10 \%$ da população ativa da Alemanha fazia uso dessa medida para sobreviver. Essa renda mínima é assegurada de forma residual, quando 
os outros benefícios sociais se esgotam ou não são suficientes para a garantia de um mínimo social (BAHLE; HUBL, 2011).

Reconhece-se que, todos os direitos são custosos, porque o que se utiliza para garantilos têm um custo (HOLMES et al, 2011). Custo este que é, efetivamente financeiro. Sob o ponto de vista de recursos financeiros destinados à concretização do mínimo existencial, é possível afirmar que a Constituição Federal de 1988 ocupou-se com rigor da matéria inclusive na Assistência Social, uma vez que através do artigo 204, da CRFB de 1988, é possível perceber que as ações governamentais na área da assistência social serão realizadas com recursos do orçamento da seguridade social, além de outras fontes (BRASIL, 1988).

A concretização do mínimo existencial no viés da assistencial social é de competência comum da União, dos Estados e dos Municípios, em aplicação analógica da interpretação dada ao art. 23, II, da Constituição Federal, pelo Supremo Tribunal Federal no julgamento do Recurso Extraordinário $\mathrm{n}^{\circ}$ 855.178, no qual restou reconhecida a responsabilidade solidária dos três entes pela prestação de serviços de saúde. Em não havendo justificativa razoável para tratamento distinto, vê-se que caberá às três esferas a adoção de medidas no sentido de promover a assistência pública.

O artigo 204, inciso I, da Constituição Federal de 1988 estabelece que, no âmbito da assistência social haverá a descentralização político-administrativa, com atribuições cabíveis às esferas federal, estadual e municipal.

As ações que se pautam pelo princípio da solidariedade não são somente aquelas que envolvem as relações entre Estados (MORAIS; MASSÁU, 2011), como também aquelas que se desenvolvem entre o Estado e seus cidadãos, o que pode ser extraído da interpretação do artigo $3^{\circ}$, inciso I, da CRFB. Tal imposição é refletida pelo ainda vigente sistema previdenciário orientado pela solidariedade inter-geracional, ou seja, as gerações atuais vertem contribuições para que idosos, inválidos, enfermos, tenham condições financeiras de gozar de benefícios previdenciários, os quais estão ligados à sobrevivência digna do indivíduo e, portanto, ao mínimo existencial. 
Como bem leciona Guilherme Camargo Massaú (2016), atualmente, no âmbito da solidariedade, o indivíduo coloca o interesse comunitário à frente do interesse individual, fazendo com que a solidariedade domine a comunidade.

Ainda, Paulo Sérgio Rosso (ROSSO, 2007) afirma que o Estado social moderno distingue-se do Estado liberal, também, no aspecto da solidariedade, uma vez que o Estado liberal põe a liberdade em patamar de maior relevância, relegando a solidariedade a um aspecto do indivíduo, enquanto a solidariedade no Estado Social moderno é assumida, inclusive, pelo Estado que pretende corrigir as desigualdades, protegendo os mais fracos. (ROSSO, 2007). Como bem leciona Gilberto Bercovici (BERCOVICI, 2003), os direitos sociais são também chamados de direitos de prestação ligados ao princípio da igualdade material que dependem de prestações diretas ou indiretas do Estado para que os cidadãos possam usufrui-los.

Exemplo que merece destaque de materialização do princípio da solidariedade, também no âmbito previdenciário, diz respeito à possibilidade de gozo de benefício previdenciário decorrente de acidente de trabalho por parte de empregado que nunca tenha vertido sequer uma contribuição previdenciária. Assim, o princípio da solidariedade, através da legislação, impõe à coletividade que realiza os recolhimentos, o dever de amparar financeiramente o trabalhador acidentado, garantindo-lhe condições de uma existência minimamente digna.

O foco da solidariedade não deve estar voltado somente para as práticas do Estado, é imperioso que se reconheça o dever normativo de solidariedade por partes dos indivíduos, como já se explicitou com os exemplos acima e com a justa finalidade de assegurar aos indivíduos menos favorecidos que tenham condições básicas de exercício de liberdades. Conforme HOLMES et al (2011), a liberdade corretamente compreendida não impede que haja dependência do governo, mas sim que um governo afirmativo dê condições materiais para que ela, liberdade, realmente exista.

Destaque-se, por fim, que há uma manifestação de solidariedade também por parte da sociedade, com exemplos de pessoas que fazem compras para que idosos não deixem suas residências, pessoas jurídicas de direito privado doam materiais médicos e hospitalares, cestas básicas também como manifestação do dever normativo de solidariedade. 


\section{CONSIDERAÇÕES FINAIS.}

Embora não haja uma tradução literal e perfeita do termo daseinsvorsorge, é possível relacionar o instituto com o mínimo existencial, reconhecendo-se que há uma obrigação estatal de provimento de serviços públicos básicos com o objetivo de assegurar o mínimo existencial.

Constata-se também, que há um necessário envolvimento do Estado e dos indivíduos com o dever de concretização dos direitos sociais que materializam o mínimo existencial e, portanto, a dignidade da pessoa humana, sem descuidar que os direitos sociais devem ser assegurados ao cidadão dentro dos parâmetros máximos possíveis (JUNIOR et al., 2018).

Verificou-se, ainda, que o princípio da solidariedade não recebe o devido tratamento doutrinário no Brasil, com escassos trabalhos que abordem o tema com a profundida que merece. Inclusive porque este princípio é a base para uma série de direitos e deveres estabelecidos no ordenamento jurídico brasileiro, daí a relevância do caráter normativo da solidariedade.

Embora não se possa descuidar que há uma necessária vinculação entre a efetividade dos direitos e a existência de recursos públicos, é imprescindível que os poderes públicos tenham as suas práticas norteadas pelo cumprimento do texto constitucional como prioridade absoluta, o que passa pela garantia do mínimo existencial como ponto de partida e também de chegada para que o princípio da solidariedade mostre-se efetivo.

É fundamental a existência, no Brasil, de um instituto nos moldes da minimum income protection europeia, para que seja garantido um padrão mínimo de vida a um maior número de pessoas especialmente no período de pandemia COVID-19 que vivencia o país.

O exemplo brasileiro do Auxílio Emergencial deve ser recebido como relevante, no entanto, é preciso que sejam ampliados os estudos acerca da sua possível insuficiência, bem como sejam ampliados os programas definitivos de transferência de renda, abrangendo um maior número de cidadãos e com uma melhora na renda básica mensal, com o intuito de que se proporcione aos indivíduos uma efetiva condição mínima de existência digna e exercício de suas liberdades. 


\section{REFERÊNCIAS}

ABRAMOVICH, Victor, CURTIS, Cristian. Direitos sociais são exigíveis. Trad. Luis Carlos Stephanov. Editora Dom Quixote, Porto Alegre, 2011.

BAHLE, Thomas; HUBL, Vanessa. The last safety net, A handbook of minimum income protection in Europe. Bristol, UK: The policy press.

BARROSO, Luís Roberto. Curso de Direito Constitucional Contemporâneo. - 4 ed. - São Paulo. Saraiva, 2013.

BERCOVICI, Gilberto. Entre o Estado Total e o Estado Social: Atualidade do debate sobre direito, Estado e economia na República de Weimar. Tese de Livre Docência. 172 p. Disponível em: https://teses.usp.br/teses/disponiveis/livredocencia/2/tde-22092009150501/publico//Gilberto_Bercovici_TeseLD.pdf.

BRASIL. Agência Brasil . Brasil perde mais de 860 mil empregos formais em abril. Disponível em https://agenciabrasil.ebc.com.br/economia/noticia/2020-05/brasil-perde-maisde-860-mil-empregos-formais-em-abril. Acesso em 30.07.2020.

BRASIL. Constituição da República Federativa do Brasil. Disponível em http://www.planalto.gov.br/ccivil_03/constituicao/constituicao.htm. Acesso em 09.07.2019.

BRASIL. Instituto Brasileiro de Geografia e Estatística. Pesquisa Nacional por Amostra de Domicílios Contínua - $\quad$ PNAD Contínua. Disponível em https://www.ibge.gov.br/estatisticas/sociais/trabalho/9171-pesquisa-nacional-por-amostra-dedomicilios-continua-mensal.html?edicao $=28382 \& \mathrm{t}=$ destaques.

BRASIL. Instituto Nacional do Seguro Social. Disponível em http://www.previdencia.gov.br/2019/05/idosos-e-deficientes-beneficiarios-do-bpc-precisamse-registrar-no-cadastro-unico/. Acesso em 14.07.2019.

BRASIL. Lei $\mathrm{n}^{\circ} 7998$ de 11 de janeiro de 1990. Regula o Programa do Seguro-Desemprego, o Abono Salarial, institui o Fundo de Amparo ao Trabalhador, e dá outras providências. Disponível em http://www.planalto.gov.br/ccivil_03/leis/17998.htm. Acesso em 31.07.2020. BRASIL. Lei 8.742 de 7 de dezembro de 1993. Dispõe sobre a organização da Assistência social e dá outras providências. Disponível em http://www.planalto.gov.br/ccivil_03/leis/18742.htm. Acesso em 29.07.2020. 
BRASIL. Lei $\mathrm{n}^{\circ} 13.982$ de 2 de abril de 2020. Altera a Lei 8742/1993 e dispõe sobre parâmetros adicionais para acesso ao BPC e medidas excepcionais de proteção social a serem adotadas durante o período de pandemia. Disponível em http://www.planalto.gov.br/ccivil_03/_Ato2019-2022/2020/Lei/L13982.htm. Acesso em 29.07.2020.

BRASIL. Medida Provisória $n^{\circ} 905$ de 11 de novembro de 2019. Institui o contrato de trabalho verde e amarelo, altera a legislação trabalhista e dá outras providências. Disponível em http://www.planalto.gov.br/ccivil_03/_ato2019-2022/2019/Mpv/mpv905.htm. Acesso em 29.07.2020.

BRASIL. Medida Provisória 936 de $1^{\text {o }}$ de abril de 2020. Institui o Programa de Manutenção do Emprego e da renda e dispõe sobre medidas trabalhistas complementares para enfrentamento do estado de calamidade pública e de emergência de saúde pública decorrente do coronavírus. Disponível em http://www.planalto.gov.br/ccivil_03/_ato20192022/2020/mpv/mpv936.htm. Acesso em 29.07.2020.

BRASIL. Conselho Nacional de Saúde. Recomendação no 27 de 22 de abril de 2020. Recomendações dirigidas aos Poderes Executivo, Federal e Estadual, ao Poder Legislativo e ao Poder Judiciário, ações de enfrentamento ao Coronavírus. Disponível em http://conselho.saude.gov.br/recomendacoes-cns/1132-recomendacao-n-027-de-22-de-abrilde-2020.

BRASIL. Supremo Tribunal Federal. Recurso Extraordinário no 855.178. Disponível em: http://www.stf.jus.br/portal/constituicao/artigoBd.asp\#visualizar. Acesso em 10.07.2019. BRASIL. Tribunal Regional Federal da $4^{\mathrm{a}}$ Região. Agravo de Instrumento $n^{\circ}$ 5040659.50.2019.404.0000. Disponível em:

https://jurisprudencia.trf4.jus.br/pesquisa/resultado_pesquisa.php . Acesso em 11.11.2019.

CALDAS. Ricardo W. Políticas públicas: conceitos e práticas. Série Políticas Públicas. v.7. Belo Horizonte, 2008.

CANOTILHO, J.J Gomes. O Direito Constitucional como Ciência de Direcção: o núcleo essencial de prestações sociais ou a localização incerta da socialidade (Contributo para a reabilitação da força normativa da "constituição social”). 
DEPARTAMENTO INTERSINDICAL DE ESTATÍSTICA E ESTUDOS SOCIOECONOMICOS (DIESSE).

Disponível em

https://www.dieese.org.br/analisecestabasica/salarioMinimo.html.

DINIZ, Márcio Augusto de Vasconcelos D. Estado social e princípio da solidariedade. Revista Nomos. Fortaleza, 2007. Disponível em: http://periódicos.ufc.br. DUQUE, Maria Paula. EI concepto de solidariedade. Revista de estudios Sociales. $N^{\circ}$ 46, p. 192-194. Bogotá, 2013.

FRANÇA, Phillip G. Objetivos fundamentais da República, escolhas públicas e políticas públicas: caminhos de concretização dos benefícios sociais constitucionais. Direitos Sociais e Políticas públicas I. Editora FUNJAB. Curitiba, 2013.

GODOI, M. S. de. Tributo e solidariedade social. In: GRECO, M. A.; GODOI, M. S. de. [coord.]. Solidariedade social e tributação. São Paulo: Dialética, 2005. p. 141-167. HOLMES, Stephen; SUNSTEIN, Cass. El costo de los derechos: Por qué la libertad depende de los impuestos. Editora Siglo Veintiuno, Buenos Aires 2011. JUNIOR, Dimas Pereira D; Oliveira, Ilzver de M.; Oliveira, Icone R. Direitos sociais: diálogo entre reserva do possível, mínimo existencial e necessidades humanas. Juris Poiesis - Rio de Janeiro. Vol 21 - nº 26, 30 de ago de 2018.

ITÁLIA. Constituição da República Italiana de 22 de dezembro de 1947. Disponível em https://www.senato.it/application/xmanager/projects/leg18/file/repository/relazioni/libreria/no vita/XVII/COST_PORTOGHESE.pdf.

LAZARI, de Rafael. Reserva do possível e mínimo existencial: A pretensão de eficácia da norma constitucional em face da realidade. Juruá Editora. $2^{\mathrm{a}}$ ed. Revista e Atualizada. Curitiba, 2016.

\section{LOS PRINCIPIOS DE LIMBURG SOBRE LA APLICACION DEL PACTO} INTRANCIONAL DE LOS DERECHOS ECONÓMICOS, SOCIALES Y CULTURALES.

Disponível em: http://www.derechoshumanos.unlp.edu.ar/assets/files/documentos/losprincipios-de-limburg-sobre-la-aplicacion-del-pacto-internacional-de-derechos-economicossociales-y-culturales-2.pdf. Acesso em 10.07.2019 MASSAÚ, Guilherme. O princípio republicano constituinte do mundo-da-vida do Estado Constitucional cosmopolita. Editora Unijuí. Ijuí, 2016. 
MENDES, Gilmar F; COELHO, Inocêncio M; BRANCO, Paulo Gustavo G. Curso de Direito Constitucional. 2 ed, rev. e atual. São Paulo: Saraiva, 2008.

MÉXICO, Constitución Política de los Estados Unidos Mexicanos. Disponível em http://www.sct.gob.mx/JURE/doc/cpeum.pdf. Acesso em 11.11.2019.

MORAIS, José L. B; MASSAÚ, Guilherme C. A solidariedade como elemento constitutivo da res pública. Pensar. Fortaleza,v.16 n.1, p. 151-177, jan/jun 2011.

ORGANIZAÇÃO MUNDIAL DA SAÚDE. Folha informativa - COVID-19 (doença causada pelo novo coronavírus). Atualizada em 31.07.2020, disponível em

https://www.paho.org/bra/index.php?option=com_content $\&$ view=article \&id=6101:covid19\&I temid=875). Acesso em 02.08.2020.

ORGANIZAÇÃO DAS NAÇÕES UNIDAS. Declaração Universal dos Direitos Humanos. Disponível em https://nacoesunidas.org/wp-content/uploads/2018/10/DUDH.pdf.

REDONDO, María Belén. El juez humanista: el nuevo guardián del derecho en el paradigma neoconstitucional. Cuestiones Constitucionales Revista Mexicana de Derecho Constitucional, [S.1.], p. 141-170, feb. 2019.

ROSA, A. M da. Consttitucionalismo garantista: notas lógicas. In: FERRAJOLI, Luigi (org). Garantismo, hermenêutica e (neo)constitucionalismo. Livraria do Advogado, p. 133-143. 2012.

ROSSO, Paulo Sérgio. Solidariedade e direitos fundamentais na Constituição Brasileira de 1988. In Revista eletrônica do CEJUR, Curitiba-PR, a. 2, v. 1, n.2, ago/dez/2007.

SARLET, Ingo Wolfgang. Dignidade (da pessoa) Humana e direitos fundamentais na Constituições Federal de 1988. 10 ed. - Porto Alegre: Livraria do Advogado Ed., 2019. SARLET, Ingo Wolfgang; ZOCKUN, Carolina Zancaner. Notas sobre o mínimo existencial e sua interpretação pelo STF no âmbito do controle judicial das políticas públicas com base nos direitos sociais. Rev. Investig. Const., Curitiba , v. 3, n. 2, p. 115-141, Aug, 2016.

TORRES, Ricardo Lôbo. O mínimo existencial e os Direitos fundamentais. Revista de Direito Administrativo, jul/set., Rio de Janeiro, 1989.

UNIÃO EUROPEIA, Carta dos Direitos Fundamentais da União Europeia. 2000, Disponível em https://www.cnpd.pt/bin/legis/internacional/CARTAFUNDAMENTAL.pdf. 
WAAL, Frans de. A era da empatia. Licões da natureza para uma sociedade mais gentil. Companhia das Letras, São Paulo, 2009.

YAMASHITA, Douglas. Princípio da solidariedade em direito tributário. In: GRECO, M.A; GODOI, M.S de [coord]. Solidariedade social e tributação. São Paulo: Dialética. p 59, 2005. 